\title{
Effect of clouds on direct aerosol radiative forcing of climate
}

\author{
Hong Liao and John H. Seinfeld \\ Division of Engineering and Applied Science, California Institute of Technology, Pasadena
}

\begin{abstract}
The effect of a cloud layer on top-of-atmosphere (TOA) aerosol radiative forcing is examined by means of a one-dimensional vertical column simulation. To span the range between nonabsorbing and strongly absorbing particles, $\left(\mathrm{NH}_{4}\right)_{2} \mathrm{SO}_{4}$ and soot aerosols are considered individually and in internal and external mixtures. For a cloud layer embedded within an aerosol layer it is shown that direct aerosol radiative forcing still occurs. For a nonabsorbing aerosol a maximum in (negative) forcing actually occurs for a thin cloud layer ( $100 \mathrm{~m}$ thickness for the set of parameters considered). The presence of an embedded cloud layer enhances the heating effect of soot aerosol, producing, for thick clouds, forcing values as much as a factor of 3 over those under cloud-free conditions. An absorbing aerosol layer can lead to an increase of in-cloud solar heating rates by up to $3 \%$ for the parameter values considered here. A cirrus cloud layer above an aerosol layer leads to only modest changes of TOA aerosol forcing from those in the absence of the cloud layer; thus aerosol forcing in the presence of typical cirrus clouds cannot be neglected.
\end{abstract}

\section{Introduction}

Aerosols affect climate through the scattering and absorption of solar radiation (the so-called direct effect) and through their influence on cloud properties (the so-called indirect effect) [Charlson et al., 1992; National Research Council (NRC), 1996]. There exist a number of assessments of the range of direct aerosol radiative forcing effects [Intergovernmental Panel on Climate Change (IPCC), 1995]. These include vertical column calculations [Charlson et al., 1991; Haywood et al., 1995; Nemesure et al., 1995; Pilinis et al., 1995] to three-dimensional global simulations [Kiehl and Briegleb, 1993; Boucher and Anderson, 1995; Feichter et al., 1997; Chuang et al., 1997]. Aerosol types considered include sulfates [Charlson et al., 1991; Kiehl and Briegleb, 1993; Nemesure et al., 1995; Boucher and Anderson, 1995; Feichter et al., 1997; Chuang et al., 1997], organic aerosol from biomass burning [Penner et al., 1992], soot [Penner, 1995], and a synthetic global-average mixture of inorganic and organic species [Pilinis et al., 1995]. Aside from global-scale simulations that naturally include the presence of clouds, most of the assessments of direct aerosol forcing consider a cloud-free atmosphere.

The goal of the current work is to explore systematically the radiative interactions that occur between cloud and aerosol layers. We consider incoming and outgoing solar and IR radiation in a one-dimensional vertical column of air extending to the top of the atmosphere. To explore the effect of aerosol optical properties, which are of essential importance, we assume that the aerosol can consist of pure ammonium sulfate, $\left(\mathrm{NH}_{4}\right)_{2} \mathrm{SO}_{4}$, pure elemental carbon (soot), or mixtures of the two species. Moreover, when a mixture is present, we specify this mixture to be either an internal mixture, in which every particle contains both species, or an external mixture, in which the aerosol consists of pure $\left(\mathrm{NH}_{4}\right)_{2} \mathrm{SO}_{4}$ particles and pure soot particles. The size distributions of the sulfate and soot particles are prescribed.

Copyright 1998 by the American Geophysical Union.

Paper number 97JD03455.

0148-0227/98/97JD-03455\$09.00
We seek to understand the role of clouds in modifying clearsky direct aerosol radiative forcing. Interactions of aerosols in cloud formation are extremely complex, and indeed this complexity is central to the indirect radiative effect of aerosols on climate. We do not address the effect of aerosols on cloud formation and processes in this work. By simply specifying a cloud layer to be present or not, we can explore how the presence of clouds modifies clear-sky direct aerosol radiative forcing. We separately consider the two cases of a stratus cloud and a cirrus cloud, the former lying within the aerosol layer and the latter positioned above it. For a water cloud the liquid water content and mean droplet size are specified, and the thickness (vertical extent) of the cloud is allowed to vary. One aspect of the specification of the aerosol/cloud system is the state of the aerosol inside the cloud itself when the cloud exists within the aerosol layer. With sulfate (hygroscopic) and soot (nonhygroscopic) particles, one would expect that the hygroscopic particles would be incorporated into the cloud droplets and the nonhygroscopic particles would remain as interstitial aerosol. Even so, for simplicity, we assume all particles are present as interstitial aerosol in the cloud in our calculations, and we will show later that such an assumption does not change the qualitative conclusions of this study.

The essential variables in the cloud/aerosol direct forcing problem are (1) whether a cloud is present or not; (2) whether the cloud lies within the aerosol layer (stratus) or not (cirrus); and (3) cloud thickness. Variables that will produce an effect that is either secondary or predictable, and are not studied here, include the aerosol size distribution [see Pilinis et al., 1995], cloud liquid water content, and cloud droplet size distribution.

\section{Radiative Transfer Model}

The radiative transfer model of $F u$ and Liou [1993] is used in the present study. The model is based on the $\delta$-four-stream approximation [Liou et al., 1988] to solve the radiative transfer equation in six solar wavelength bands $(0.2-0.7,0.7-1.3,1.3-1.9$, 1.9-2.5, 2.5-3.5, and 3.5-4.0 $\mu \mathrm{m})$ and 12 IR bands (2200-1900, $1900-1700,1700-1400,1400-1250,1250-1100,1100-980,980-$ 
$800,800-670,670-540,540-400,400-280$, and $\left.280-0 \mathrm{~cm}^{-1}\right)$. The model includes molecular Rayleigh scattering, gaseous absorption, and cloud effects; we have extended the model to include aerosol scattering and absorption. The model calculates total flux as the sum of direct solar and diffuse flux. The heating rate is calculated from the divergence of the net flux. To investigate the effect of aerosols and the interaction between aerosols and clouds, optical depth, single-scattering albedo, and asymmetry factor of the aerosols are calculated and combined with those of gases and cloud droplets in each wavelength range.

To enhance vertical resolution near the cloud layer, we have increased the number of vertical layers in the model from 70 to 98, giving a vertical resolution of about $100 \mathrm{~m}$ near the cloud layer. Pressure, temperature, ozone, and clear-sky water vapor mixing ratios are those from U.S. Standard Atmosphere (1976). For cloudy sky the standard atmospheric profile is used to obtain the saturation water vapor mixing ratio in cloud.

We take the solar constant to be $1376 \mathrm{~W} \mathrm{~m}^{-2}$ and the IR surface emissivity to be 1.0. The solar surface albedo is 0.2 in all calculations except in section 9 where we study the effect of surface albedo. Mixing ratios of $\mathrm{CO}_{2}, \mathrm{CH}_{4}$, and $\mathrm{N}_{2} \mathrm{O}$ are assumed to be uniform throughout the troposphere at $356,1.7$, and $0.31 \mathrm{ppm}$, respectively.

The code ELSIE [Sloane, 1984, 1986; Sloane and Wolff, 1985; Sloane et al., 1991] is used to calculate aerosol optical properties. ELSIE considers particles to be internal mixtures and includes nitrate, sulfate, organic carbon, elemental carbon, and residual mass (dust). Particle index of refraction is calculated as a volume-weighted average of the indices of refraction of its components. For an external mixture of $\left(\mathrm{NH}_{4}\right)_{2} \mathrm{SO}_{4}$ and elemental carbon (soot), the single-scattering albedo $\omega$ and asymmetry factor $g$ in each size range are calculated by [d'Almeida et al., 1991]

$$
\begin{gathered}
\omega=\frac{\omega_{s} \sigma_{s}+\omega_{c} \sigma_{c}}{\sigma_{s}+\sigma_{c}} \\
g=\frac{g_{s} \omega_{s} \sigma_{s}+g_{c} \omega_{c} \sigma_{c}}{\omega_{s} \sigma_{s}+\omega_{c} \sigma_{c}}
\end{gathered}
$$

where $\sigma_{s}$ and $\sigma_{c}$ are the total extinction cross sections of sulfate and carbon particles, respectively; $\omega_{s}$ and $\omega_{c}$ are the singlescattering albedos of sulfate and carbon particles, and $g_{s}$ and $g_{c}$ are the corresponding asymmetry factors.

\section{Aerosol and Cloud Specification}

A uniform aerosol layer from the Earth's surface to $5 \mathrm{~km}$ is assumed. The two possible aerosol constituents are $\left(\mathrm{NH}_{4}\right)_{2} \mathrm{SO}_{4}$ and soot. The dry mass size distributions of $\left(\mathrm{NH}_{4}\right)_{2} \mathrm{SO}_{4}$ and soot particles are assumed to be lognormal, with median diameter of $0.5 \mu \mathrm{m}$ and geometric standard deviation of 2.0 for $\left(\mathrm{NH}_{4}\right)_{2} \mathrm{SO}_{4}$ and $0.1 \mu \mathrm{m}$ and 2.0 for soot particles. Refractive indices for $\left(\mathrm{NH}_{4}\right)_{2} \mathrm{SO}_{4}$, soot, and water are from Toon et al. [1976], World Climate Program (WCP) [1986], and Hale and Querry [1973], respectively. Densities are taken to be $1.76 \mathrm{~g} \mathrm{~cm}^{-3}$ for $\left(\mathrm{NH}_{4}\right)_{2} \mathrm{SO}_{4}$ and $1.70 \mathrm{~g} \mathrm{~cm}^{-3}$ for soot. In a humid atmosphere, total aerosol volume is the sum of the dry volumes of the individual components plus the volume of water associated with the hygroscopic components. Liquid water volume associated with pure $\left(\mathrm{NH}_{4}\right)_{2} \mathrm{SO}_{4}$ particles and mixed $\left(\mathrm{NH}_{4}\right)_{2} \mathrm{SO}_{4}$ soot particles is calculated by using thermodynamic theory [Pilinis and
Seinfeld, 1987; Kim et al., 1993a,b]. It is assumed that soot is nonhygroscopic.

A uniform relative humidity of $50 \%$ is a reasonable approximation for the lowest $5 \mathrm{~km}$ of the U.S. Standard Atmosphere and is assumed to calculate the optical properties of the uniform aerosol layer. Since the relative humidity of deliquescence (RHD) of pure $\left(\mathrm{NH}_{4}\right)_{2} \mathrm{SO}_{4}$ is $80 \%$, particles initially dry would remain dry at $50 \% \mathrm{RH}$. There is evidence, however, that atmospheric particles below their RHD frequently exist in the metastable state corresponding to the curve obtained by drying out an initially wet particle. In such a case, a detailed thermodynamic calculation predicts that the ratio of wet to dry particle diameters for pure $\left(\mathrm{NH}_{4}\right)_{2} \mathrm{SO}_{4}$ at $50 \% \mathrm{RH}$ is 1.21 [Pilinis and Seinfeld, 1987; Kim et al., 1993a,b].

$\mathrm{A}\left(\mathrm{NH}_{4}\right)_{2} \mathrm{SO}_{4}$ concentration of $2.5 \mu \mathrm{g} \mathrm{m}^{-3}$ is representative of continental conditions, as compared with an estimated globalmean sulfate concentration of $0.57 \mu \mathrm{g} \mathrm{m}^{-3}$ distributed over the lowest $12 \mathrm{~km}$ of the atmosphere [Andreae, 1995]. (If this globalmean level is instead distributed over a layer only $5 \mathrm{~km}$ thick, it increases to $1.3 \mu_{\mathrm{g} \mathrm{m}^{-3}}$.) When a pure soot aerosol only is considered, the mass concentration is assumed to be $0.5 \mu \mathrm{g} \mathrm{m}^{-3}$. For comparison, Chylek et al. [1996] estimated an upper limit global-mean concentration of black carbon of $0.5 \mu \mathrm{g} \mathrm{m}^{-3}$ uniformly distributed over a $1 \mathrm{~km}$ thick layer. The total mass concentration of internal and external mixtures is $3.0 \mu \mathrm{g} \mathrm{m}^{-3}$, consisting of $2.5 \mu \mathrm{g} \mathrm{m}^{-3}\left(\mathrm{NH}_{4}\right)_{2} \mathrm{SO}_{4}$ and $0.5 \mu \mathrm{g} \mathrm{m}^{-3}$ soot. The soot/sulfate mixture considered here is roughly representative of northem hemisphere continental conditions.

When a stratus cloud is present we assume a vertically uniform cloud layer centered at $900 \mathrm{~m}$ altitude with a thickness that is varied over the range of 100 to $1000 \mathrm{~m}$. A liquid water content of $0.2 \mathrm{~g} \mathrm{~m}^{-3}$ and an effective cloud droplet radius of $10 \mu \mathrm{m}$ are assumed. For cirrus cloud simulations we assume a cloud layer with a thickness of $2000 \mathrm{~m}$ extending from 7000 to $9000 \mathrm{~m}$ altitude. At a temperature of about $-40^{\circ} \mathrm{C}$ at this altitude, a cloud ice content of $9.177 \times 10^{-3} \mathrm{~g} \mathrm{~m}^{-3}$ and a mean effective particle size of $64.1 \mu \mathrm{m}$ are assumed [Fu and Liou, 1993].

\section{TOA Aerosol Forcing in Cloud-Free Conditions}

Top-of-atmosphere (TOA) aerosol radiative forcing is defined as $-\left(F_{a} \uparrow-F_{o} \uparrow\right)$, where $F_{o} \uparrow$ and $F_{a} \uparrow$ are the upward solar fluxes for aerosol-free and aerosol-laden cases, respectively. The negative sign implies that if $F_{a} \uparrow>F_{o} \uparrow$, aerosols produce a cooling

Table 1. (TOA) Aerosol Radiative Forcing Under Cloud Free Conditions

\begin{tabular}{lcc}
\hline Aerosol Composition & Total Dry Mass & $\begin{array}{c}\text { TOA Forcing, }^{\mathrm{W}} \\
\mathrm{W} \mathrm{m}^{-2}\end{array}$ \\
\hline Pure $\left(\mathrm{NH}_{4}\right)_{2} \mathrm{SO}_{4}$ & $2.5(1.1)$ & -2.0 \\
Pure soot & $0.5(0)$ & +5.5 \\
Internal mixture & $3.0(1.1)$ & +4.6 \\
External mixture & $3.0(1.1)$ & +3.6 \\
\hline
\end{tabular}

(TOA) incoming solar flux $=1376 \mathrm{~W} \mathrm{~m}^{-2}$. Solar zenith angle $\theta_{0}=0^{\circ}$

$F_{o} \uparrow=253.8 \mathrm{~W} \mathrm{~m}^{-2}$. Surface albedo $=0.2$.

a Water mass at $50 \%$ RH is given in parentheses. 
effect and vice versa. $F_{o} \uparrow$ is calculated for clear sky, including Rayleigh scattering and molecular absorption; then $F_{a} \uparrow$ is calculated with the addition of the aerosol layer.

Aerosol radiative forcing for $\left(\mathrm{NH}_{4}\right)_{2} \mathrm{SO}_{4}$, soot, and mixtures at solar zenith angle $\theta_{o}=0^{\circ}$ is given in Table 1 . A $5 \mathrm{~km}$ thick layer of pure $\left(\mathrm{NH}_{4}\right)_{2} \mathrm{SO}_{4}$ aerosol at a dry mass concentration of $2.5 \mu \mathrm{g}$ $\mathrm{m}^{-3}$ produces a forcing of $-2.0 \mathrm{~W} \mathrm{~m}^{-2}$. At the other extreme a comparable layer of pure soot aerosol at a concentration of $0.5 \mu \mathrm{g}$ $\mathrm{m}^{-3}$ yields a forcing of $+5.5 \mathrm{~W} \mathrm{~m}^{-2}$, a heating effect. TOA aerosol forcing is sensitive to the aerosol mixing state. With every particle exhibiting some absorption, an internally mixed aerosol layer produces a larger warming effect than the corresponding external mixture; the TOA forcing of the intemal mixture is $+4.6 \mathrm{~W} \mathrm{~m}^{-2}$, whereas that of the external mixture is $+3.6 \mathrm{~W} \mathrm{~m}^{-2}$.

\section{TOA Forcing by Aerosols in the Presence of a Stratus Cloud}

TOA radiative forcing of aerosols in the presence of a cloud layer is defined as $-\left(F_{a+c} \uparrow-F_{c} \uparrow\right)$, where $F_{a+c} \uparrow$ and $F_{c} \uparrow$ are upward solar fluxes at TOA for cloudy sky with aerosols and cloudy sky without aerosols, respectively. The quantity $-\left(F_{a+c} \uparrow-F, \uparrow\right)$ is shown as a function of cloud thickness in Figure 1 for $\left(\mathrm{NH}_{4}\right)_{2} \mathrm{SO}_{4}$, soot, and each of the mixtures. The TOA forcing effect of a pure $\left(\mathrm{NH}_{4}\right)_{2} \mathrm{SO}_{4}$ layer increases (greater negative effect, i.e., cooling) when a thin cloud is present but rapidly reaches a maximum at a cloud thickness of $100 \mathrm{~m}$ and then slowly decreases with increasing cloud thickness. For a pure soot aerosol, TOA forcing, in this case positive, i.e., heating, increases monotonically with increasing cloud thickness. The forcing effects of internally and externally mixed aerosols exhibit the same overall tendency of increasing forcing with increasing cloud thickness, except that when $\left(\mathrm{NH}_{4}\right)_{2} \mathrm{SO}_{4}$ is present the forcing tends in the direction of cooling when a thin cloud is present, reaches a minimum, and then increases. The forcing curve for pure soot begins above that of the internal mixture at zero cloud thickness, but the two curves cross at a cloud thickness of about $350 \mathrm{~m}$; for clouds thicker than this, the internal mixture produces greater (positive) forcing than the pure soot aerosol.
Consider first the behavior of the pure $\left(\mathrm{NH}_{4}\right)_{2} \mathrm{SO}_{4}$ forcing as cloud thickness increases from zero. The maximum in negative forcing can be explained as follows: A cloud layer of $100 \mathrm{~m}$ thickness transmits about $85 \%$ of the downward solar flux and scatters the incident radiation from its original path. Since the upscatter fraction for diffuse radiation is larger than the upscatter fraction for incident radiation with the Sun at zenith [Wiscombe and Grams, 1976], the aerosols located below the cloud layer have larger negative forcing than they have in the absence of the thin cloud layer. For clouds thicker than this, the percentage of the solar beam transmitted through the cloud is smaller, so the contribution of the aerosols below the cloud to TOA forcing is decreased. Even when the particles contain a fraction of soot and are producing an overall heating effect, this balance betweencloud and below-cloud aerosol scattering still produces a cloud thickness at which heating is at a minimum, regardless of whether the particles are internally or externally mixed. It is apparent that the cloud thickness at which negative forcing is maximum or positive forcing is minimum depends on the solar zenith angle.

Since most of the soot aerosol resides above the cloud layer in our scenario, as cloud thickness increases, the soot aerosol above the cloud absorbs more radiation since the cloud is more effective at scattering increasing solar radiation back to space than either the aerosol layer alone or the Earth's surface.

We note from Figure 1 that for the case of pure $\left(\mathrm{NH}_{4}\right)_{2} \mathrm{SO}_{4}$ aerosol, (1) when the cloud layer is thick, $F_{a+c} \uparrow-F_{c} \uparrow<F_{a} \uparrow-F_{o} \uparrow$, and (2) the thicker the cloud layer, the smaller $F_{a+c}{ }^{c} \uparrow-F_{c} \uparrow$. This result can be understood by using the adding method for multiple scattering [ $\mathrm{Liou}, 1980]$. When the cloud layer is thick, aerosol below the cloud layer can be neglected. Let $R_{a}$ and $T_{a}$ denote the albedo and total (direct plus diffuse) transmission function for the aerosol layer above the cloud layer, and let $R_{c}$ and $T_{c}$ be the corresponding values for the cloud layer. The albedo of the cloud-aerosol combination is [Liou, 1980]

$$
R_{a+c}=R_{a}+R_{c} \frac{T_{a}^{2}}{1-R_{a} R_{c}}
$$

Since pure $\left(\mathrm{NH}_{4}\right)_{2} \mathrm{SO}_{4}$ can be considered as nonabsorbing in the solar portion of the spectrum, $R_{a}+T_{a}=1$. Thus (3) becomes

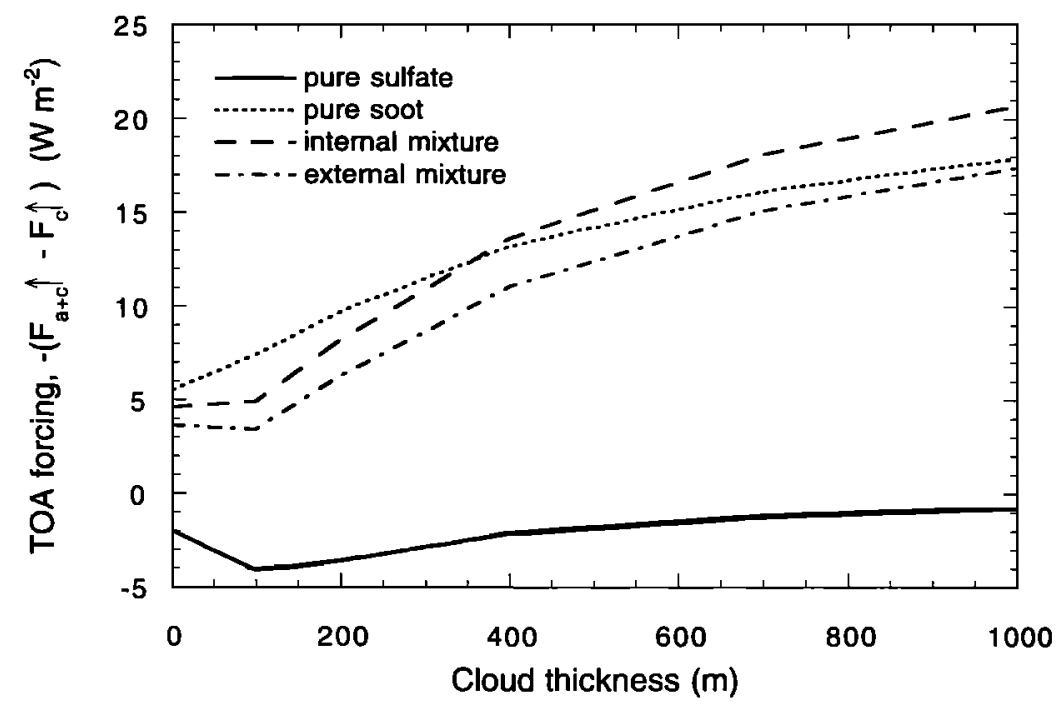

Figure 1. Top-of-atmosphere (TOA) radiative forcing, $-\left(F_{a+c} \uparrow-F_{c} \uparrow\right)$, as a function of cloud thickness for different aerosol compositions. Solar zenith angle $=0^{\circ}$. 


$$
R_{a+c}=R_{a}+R_{c} \frac{\left(1-R_{a}\right)^{2}}{1-R_{a} R_{c}}
$$

Since $0<R_{a}<1$ and $0<R_{c}<1, R_{a}+R_{c}<2$. As a result

$$
\frac{\left(1-R_{a}\right)^{2}}{1-R_{a} R_{c}}<1
$$

and thus

$$
R_{a+c}<R_{a}+R_{c}
$$

Equation (6) indicates that the albedo of the combined aerosolcloud system is less than the sum of the individual values of the aerosol and cloud layers. This is a result of the multiple scattering occurring between the cloud and the aerosol layers. Stated differently, $R_{a+c}-R_{c}<R_{a}$; that is, the increase in albedo that occurs when an aerosol layer is added to a cloud layer is less than that of the aerosol layer alone. Since $F_{a+c} \uparrow-F_{c} \uparrow$ $=F_{T} T^{2}\left(R_{a+c}-R_{c}\right)$ and $F_{a} \uparrow-F_{o} \uparrow=F_{T} T^{2} R_{a}$, where $F_{T}$ is the incident solar flux at TOA and $T$ is the transmission of the atmosphere above the aerosol layer, $F_{a+c} \uparrow-F_{c} \uparrow<F_{a} \uparrow-F_{o} \uparrow$. The quantity $F_{a+c} \uparrow-F_{c} \uparrow$ decreases as the cloud layer gets thicker. As cloud thickness increases, i.e., $R_{c} \rightarrow 1$, it is apparent from (3) that $\left(R_{a+c}-R_{c}\right) \rightarrow 0$. At a cloud albedo of unity, all incident radiation is sent back to space and the presence of the aerosol layer has no effect.

An intriguing property of the internally mixed aerosol case is the crossover of forcing for the pure soot and internal mixture at a cloud thickness of about $350 \mathrm{~m}$. For both cases the mass concentration of soot is $0.5 \mu \mathrm{g} \mathrm{m}^{-3}$. However, the internal mixture aerosol contains $2.5 \mu \mathrm{g} \mathrm{m}^{-3}$ additional $\left(\mathrm{NH}_{4}\right)_{2} \mathrm{SO}_{4}$. The median dry diameter of $\left(\mathrm{NH}_{4}\right)_{2} \mathrm{SO}_{4}$ is $0.5 \mu \mathrm{m}$, whereas that of the pure soot is $0.1 \mu \mathrm{m}$. The larger particle size and presence of nonabsorbing $\left(\mathrm{NH}_{4}\right)_{2} \mathrm{SO}_{4}$ make the scattering effect of the internally mixed aerosol much stronger than that of pure soot; the scattering coefficient for the internal mixture is about 38 times higher than that of pure soot. When the cloud layer is thin, the warming effect of pure soot exceeds that of the internal mixture. As the cloud thickness increases, the cooling effect from scattering is reduced, while the warming effect from absorption increases. In the external mixture the scattering coefficient is about the same as that of the internal mixture, but the absorption coefficient is slightly smaller than that of the internal mixture, so the overall aerosol does not have sufficient absorption, as cloud thickness increases, for the forcing curve to cross that of soot.

For simplicity we have assumed that particles are present as interstitial aerosol in the cloud. Whereas this assumption is likely to be a good one for soot aerosol, in-cloud $\left(\mathrm{NH}_{4}\right)_{2} \mathrm{SO}_{4}$ and the internally mixed aerosols, because of their solubility in water, have probably been scavenged by cloud droplets. The question is what is the effect on forcing calculations if the $\left(\mathrm{NH}_{4}\right)_{2} \mathrm{SO}_{4}$ particles and internally mixed aerosol particles are retained in the cloud. For a $1000 \mathrm{~m}$ thick cloud the following results are obtained from our experiments: (1) for the case of pure $\left(\mathrm{NH}_{4}\right)_{2} \mathrm{SO}_{4}$, removing the $\left(\mathrm{NH}_{4}\right)_{2} \mathrm{SO}_{4}$ particles from the cloud layer leads to a decrease in the absolute value of forcing of $21 \%$. At this point total net aerosol forcing is, however, very small; (2) for the external mixture, removing the $\left(\mathrm{NH}_{4}\right)_{2} \mathrm{SO}_{4}$ particles and leaving the soot particles inside the cloud cause an increase of only $0.6 \%$ in TOA forcing; (3) removing the internally mixed aerosol particles inside the cloud decreases the TOA forcing of the internal mixture by $16 \%$. Thus the qualitative conclusions of the study do not change depending on whether soluble aerosol is retained in cloud or not.

Another assumption that we made in the calculations is that of a uniform aerosol layer, which has constant mass concentration from the surface to $5 \mathrm{~km}$ altitude. We can examine the effect of vertical variation of aerosol mass concentrations. For pure soot aerosol, which has the same column burden as in the uniform aerosol layer case, its mass concentration is now assumed to decrease linearly from its surface value to $1 / 10$ of its surface value at $3 \mathrm{~km}$ altitude and then remain constant from $3 \mathrm{~km}$ to 5 km altitude. Compared with the uniform aerosol layer, this more realistic vertical profile produces almost identical TOA forcing under clear-sky conditions, but the TOA forcing is consistently smaller when a cloud layer is present because less aerosol is above the cloud layer. For example, in the presence of a $1000 \mathrm{~m}$ thick stratus cloud the TOA forcing of soot is $17.9 \mathrm{~W} \mathrm{~m}^{-2}$ when the aerosol layer is uniform, while it is $13.5 \mathrm{~W} \mathrm{~m}^{-2}$ with the assumed vertical profile. In this case, about $72 \%$ of the total soot mass is above the cloud layer for the uniform aerosol layer, while only $40 \%$ of the total soot mass is above the cloud layer for the case with vertical mass variation. A similar study for pure $\left(\mathrm{NH}_{4}\right)_{2} \mathrm{SO}_{4}$ aerosol shows that the TOA forcing is not sensitive to vertical mass variation, either under clear-sky or under cloudysky conditions. Thus vertical variation of aerosol mass concentration affects the values of TOA forcing but does not change the essential physics of the problem.

\section{TOA Aerosol Forcing in the Presence of a Cirrus Cloud}

With a $2000 \mathrm{~m}$ thick cirrus cloud lying over the aerosol layer, at $\theta_{o}=0^{\circ}$, TOA forcing, $-\left(F_{a+c} \uparrow-F_{c} \uparrow\right)$, of pure $\left(\mathrm{NH}_{4}\right)_{2} \mathrm{SO}_{4}$ and soot layers are -3.3 and $+4.9 \mathrm{~W} \mathrm{~m}^{-2}$, respectively. These are to be compared with clear-sky TOA forcings of -2.0 and $+5.5 \mathrm{~W} \mathrm{~m}^{-2}$ (Table 1). It is noteworthy that the cirrus cloud enhances the negative forcing of $\left(\mathrm{NH}_{4}\right)_{2} \mathrm{SO}_{4}$ but reduces the positive forcing of soot. Because the ice water content of the cirrus cloud $\left(9.177 \times 10^{-3} \mathrm{~g} \mathrm{~m}^{-3}\right)$ is much smaller than the liquid water content of the stratus cloud $\left(0.2 \mathrm{~g} \mathrm{~m}^{-3}\right)$, the optical depth of a $2000 \mathrm{~m}$ cirrus cloud ( 0.93 in the wavelength band 0.2 to $0.7 \mu \mathrm{m}$ ) is much smaller than that of even a $100 \mathrm{~m}$ water cloud ( 3.10 in the same wavelength band); transmission of the cirrus cloud is about $90 \%$ while that of a $100 \mathrm{~m}$ stratus cloud is about $85 \%$. The reason that the cirrus cloud slightly reduces the positive forcing of a soot aerosol layer lying below it is that absorption is proportional to radiation intensity, which is slightly reduced by the cirrus cloud. The explanation of why the cirrus cloud enhances negative sulfate forcing is that the cloud scatters the direction of the incident radiation from its $\theta_{o}=0^{\circ}$ path, causing a forcing increase similar to that which occurs with increasing solar zenith angle. It is clear that forcing by an aerosol layer underlying a cirrus layer cannot be neglected.

\section{Heating Rates}

The climate forcing effects of aerosols can be seen clearly in the vertical profiles of the heating rates. Under aerosol- and cloud-free conditions (Figure 2), heating caused by shortwave radiation is almost uniform in the troposphere. Solar heating is a result of gaseous absorption, and IR cooling is mainly a result of water vapor emission. 


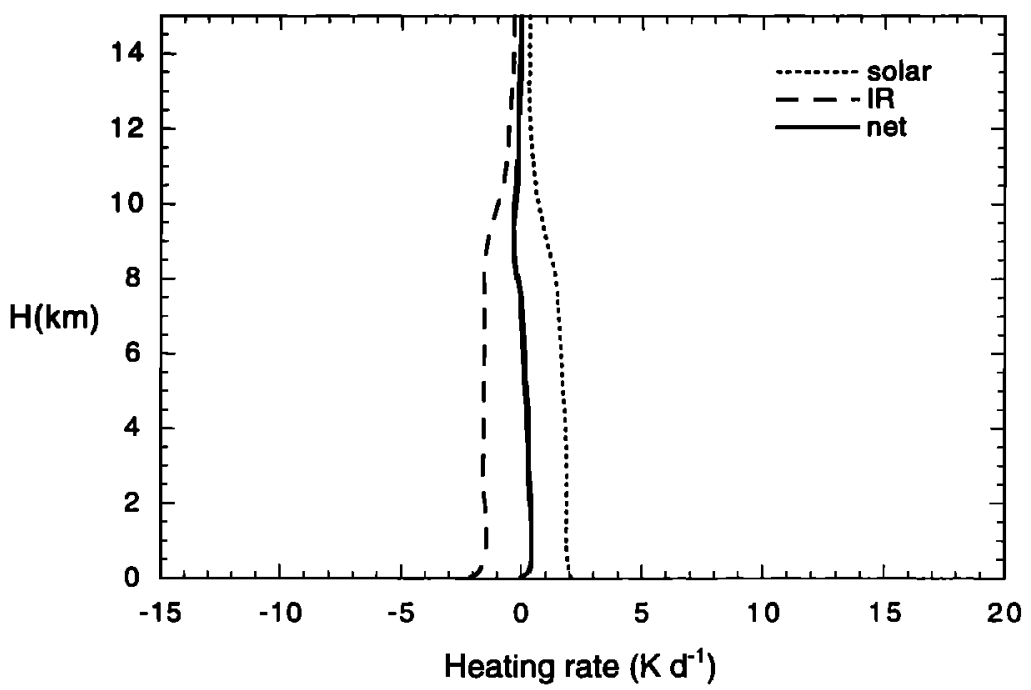

Figure 2. Atmospheric heating rates (solar, infrared, and net) for the aerosol- free and cloud-free atmosphere.

In the presence of a 1000 thick stratus cloud and absence of aerosols (Figure 3), shortwave heating rates reach a maximum below the top of the cloud layer, corresponding to the point of maximum upward and downward solar fluxes (not shown). At the bottom of the cloud layer, there is slight IR heating because the absorption of IR radiation emitted from the Earth's surface and the overlying cloud overweigh IR emission. At the top of the cloud layer, on the contrary, there is strong cooling because the IR emission there is much larger than the absorption of IR radiation emitted by the underlying cloud.

Figure 4 shows the difference in solar heating rates for four cases: (1) $\left(\mathrm{NH}_{4}\right)_{2} \mathrm{SO}_{4}$ layer versus clear sky (no cloud, no aerosol); (2) soot layer versus clear sky (no cloud, no aerosol); (3) $\left(\mathrm{NH}_{4}\right)_{2} \mathrm{SO}_{4}$ layer with cloud versus cloudy sky (no aerosol); and (4) soot layer with cloud versus cloudy sky (no aerosol). The cloud layer is $1000 \mathrm{~m}$ thick stratus cloud in cases (3) and (4). For a layer of pure $\left(\mathrm{NH}_{4}\right)_{2} \mathrm{SO}_{4}$ aerosol the difference in solar heating rate versus the cloud-free and aerosol-free atmosphere (Figure 2) is negligible, and the cooling effect of the aerosol layer is exclusively located at the surface. For a soot layer, on the other hand, a difference in solar heating rate of about $0.2 \mathrm{~K} \mathrm{~d}^{-1}$ is produced in the layer versus the cloud-free and aerosol-free atmosphere (Figure 2), about a $10 \%$ increase. When an $\left(\mathrm{NH}_{4}\right)_{2} \mathrm{SO}_{4}$ aerosol layer is added to a cloud layer, the change in solar heating is quite small, a slight cooling effect near cloud top that is negligible when compared to the approximately $30 \mathrm{~K} \mathrm{~d}^{-1}$ solar heating rate near the top of the cloud (Figure 3 ). The most interesting effect is that which occurs when a pure soot aerosol layer is present with a cloud layer. A differential solar heating rate of about $0.5 \mathrm{~K} \mathrm{~d}^{-1}$ occurs below the top of the cloud layer, corresponding to the maximum upward and downward solar fluxes. This $0.5 \mathrm{~K} \mathrm{~d}^{-1}$ is to be compared to the aerosol-free peak cloud heating rate of 20 to $30 \mathrm{~K} \mathrm{~d}^{-1}$ (Figure 3). Thus presence of the pure soot aerosol adds about $3 \%$ to the in-cloud solar heating rate, a small but nonnegligible effect.

Figure 5 shows the differential solar heating rate again for the internal and external mixtures. As expected, the internal mixture produces a larger heating effect than the external mixture.

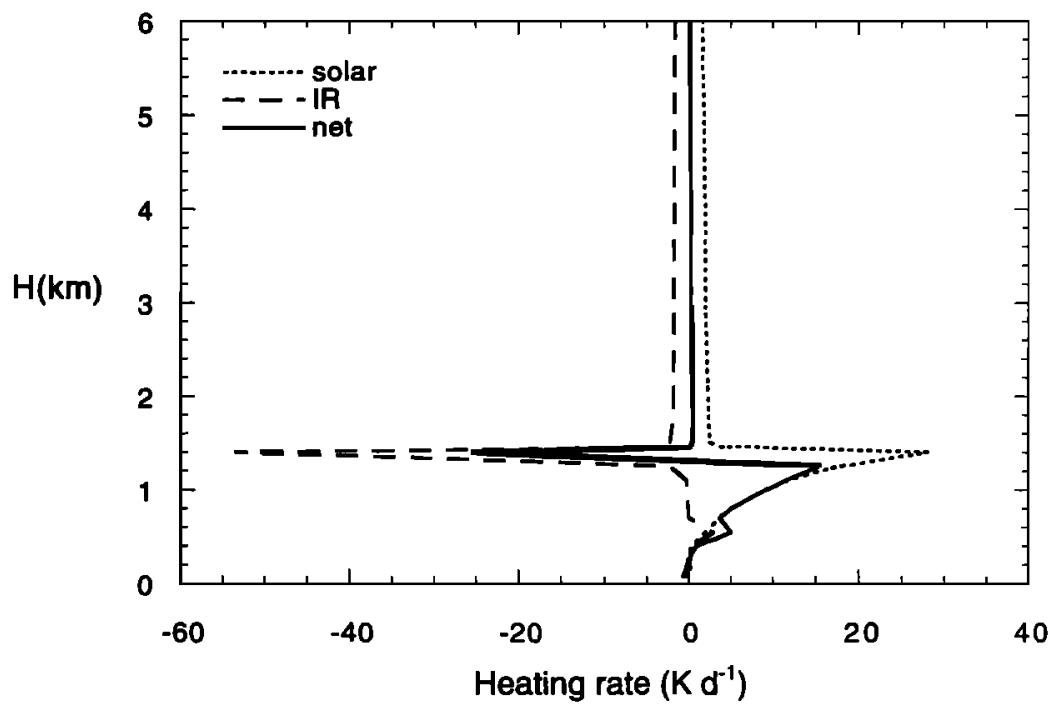

Figure 3. Atmospheric heating rates (solar, infrared, and net) for $1000 \mathrm{~m}$ thick cloud centered at $900 \mathrm{~m}$ altitude. 


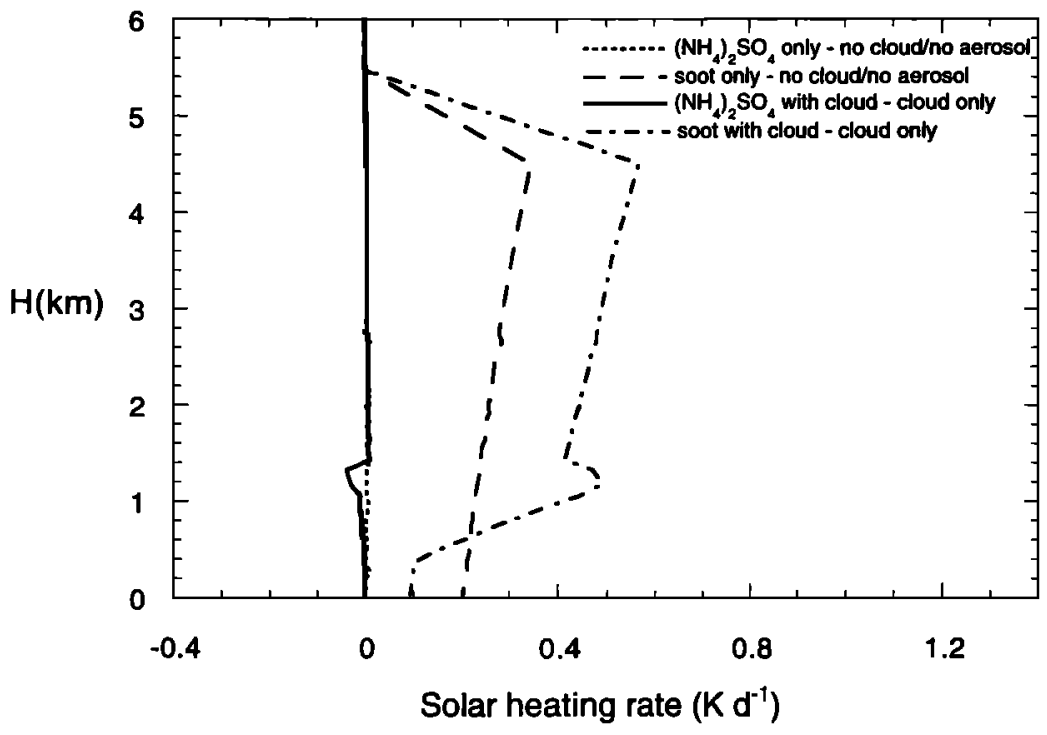

Figure 4. Differential solar heating rate for pure $\left(\mathrm{NH}_{4}\right)_{2} \mathrm{SO}_{4}$ and soot aerosol layers with and without cloud layer present. Cloud thickness $1000 \mathrm{~m}$.

Compared with clear-sky forcing, the presence of a $1000 \mathrm{~m}$ thick stratus cloud produces an increase of about $0.2 \mathrm{~K} \mathrm{~d}^{-1}$ in solar heating rate throughout the portion of the aerosol layer which is located above the cloud for both internal and external mixtures.

An increase in in-cloud solar heating rate of $3 \%$ as a result of the presence of an absorbing aerosol can be expected to lead to some alteration of cloud properties. This represents a cloudaerosol feedback mechanism, as noted by Hansen and Ruedy [1997].

Since the optical depth of the cirrus cloud is very small, the differential heating rates caused by $\left(\mathrm{NH}_{4}\right)_{2} \mathrm{SO}_{4}$ or soot in the presence of an overlying cirmus cloud are essentially identical to those caused by $\left(\mathrm{NH}_{4}\right)_{2} \mathrm{SO}_{4}$ or soot under clear-sky conditions, respectively.

\section{Effect of Solar Zenith Angle}

In examining the effect of solar zenith angle, we consider six cases: (1) pure $\left(\mathrm{NH}_{4}\right)_{2} \mathrm{SO}_{4}$ aerosol-no cloud; (2) pure $\left(\mathrm{NH}_{4}\right)_{2} \mathrm{SO}_{4}$-stratus cloud; (3) pure soot-no cloud; (4) pure sootstratus cloud; (5) pure $\left(\mathrm{NH}_{4}\right)_{2} \mathrm{SO}_{4}$-cirrus cloud; and (6) pure soot-cirrus cloud. Cloud thickness is $1000 \mathrm{~m}$ for the stratus cloud and $2000 \mathrm{~m}$ for the cirrus cloud. TOA aerosol forcing is shown as a function of $\mu_{o}=\cos \theta_{o}$ for the six cases in Figure 6. A maximum in negative forcing for the clear-sky $\left(\mathrm{NH}_{4}\right)_{2} \mathrm{SO}_{4}$ aerosol occurs at $\mu_{o}=0.35$. The existence of such a maximum in forcing was demonstrated by Nemesure et al. [1995] and Pilinis et al. [1995]. The form of the $\left(\mathrm{NH}_{4}\right)_{2} \mathrm{SO}_{4}$ clear-sky curve as a function of solar zenith angle is consistent with that presented by Russell et al. [1997]. In the presence of the cirrus cloud the



Figure 5. Differential solar heating rate for internal and external mixtures. Cloud thickness $1000 \mathrm{~m}$. 


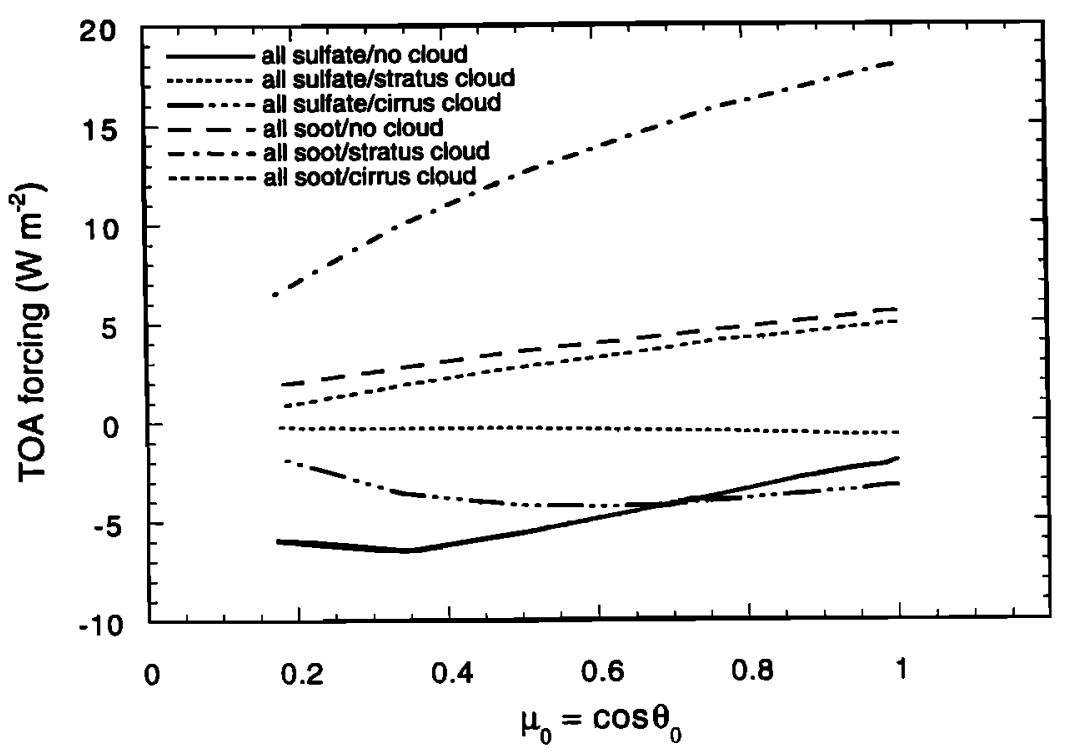

Figure 6. TOA radiative forcing as a function of $\mu_{o}=\cos \theta_{0}$ for pure $\left(\mathrm{NH}_{4}\right)_{2} \mathrm{SO}_{4}$ and soot aerosol layers with and without cloud layer present. Stratus cloud thickness $1000 \mathrm{~m}$ and cirrus cloud thickness $2000 \mathrm{~m}$.

variation of TOA forcing of $\left(\mathrm{NH}_{4}\right)_{2} \mathrm{SO}_{4}$ versus $\mu_{o}$ has the same tendency as that of $\left(\mathrm{NH}_{4}\right)_{2} \mathrm{SO}_{4}$ under clear-sky conditions, even though the maximum shifts to $\mu_{o}=0.6$ due to the effect of the cirrus cloud which scatters the incident radiation from its original path. When the stratus cloud is present, the magnitude of negative forcing is reduced, and negative forcing monotonically increases toward that at overhead Sun. As $\theta_{o}$ increases, the optical path through the cloud increases, producing the same effect as if the cloud layer is getting thicker. TOA forcing is positive for soot aerosols both with and without a cloud present with a maximum at $\theta_{o}=0^{\circ}\left(\mu_{o}=1.0\right)$.

\section{Effect of Surface Albedo}

The same cases as in section 8 are used to investigate the sensitivity of aerosol TOA forcing to surface albedo (Figure 7).
Cloud thickness is $1000 \mathrm{~m}$ for the stratus cloud and $2000 \mathrm{~m}$ for the cirrus cloud, and solar zenith angle $\theta_{o}=0^{\circ}$. TOA forcing of $\left(\mathrm{NH}_{4}\right)_{2} \mathrm{SO}_{4}$ under clear-sky conditions or with the cirrus cloud has positive values when surface albedo is larger than about 0.4 . This can be explained as follows: On one hand, absorption by the surface is increased when the aerosol layer is present and surface albedo is high. Some of the radiation that is reflected by the surface is backscattered to the surface by the aerosol layer and it is reflected again by the surface, thus the surface absorbs more radiation [Haywood et al., 1997]. On the other hand, the increase in path length of the radiation due to scattering by the aerosol and surface leads to extra gaseous absorption. The TOA forcing of soot under clear-sky conditions or with the cirrus cloud increases dramatically with increasing surface albedo, ranging from about 2 $\mathrm{W} \mathrm{m} \mathrm{m}^{-2}$ over sea surface (surface albedo $\approx 0.08$ ) to about $25 \mathrm{~W}$ $\mathrm{m}^{-2}$ over snow surface (surface albedo $\approx 0.8$ ), because the soot



Figure 7. TOA radiative forcing as a function of surface albedo for pure $\left(\mathrm{NH}_{4}\right)_{2} \mathrm{SO}_{4}$ and soot aerosol layers with and without cloud layer present. Stratus cloud thickness $1000 \mathrm{~m}$ and cirrus cloud thickness $2000 \mathrm{~m}$. 
particles absorb both incoming radiation and radiation reflected by high-albedo surfaces. The TOA forcing of $\left(\mathrm{NH}_{4}\right)_{2} \mathrm{SO}_{4}$ or soot in the presence of a stratus cloud layer is not very sensitive to surface albedo because of the shielding effect of the cloud.

\section{Conclusions}

We have examined the change in TOA radiative forcing of an aerosol layer as a result of the presence of a stratus cloud layer for pure $\left(\mathrm{NH}_{4}\right)_{2} \mathrm{SO}_{4}$ and soot aerosols and internal and external mixtures of the two species. We consider a relatively low-level ( $\sim \mathrm{km}$ altitude) cloud layer embedded within a uniform aerosol layer extending up to $5 \mathrm{~km}$ altitude. The "zeroth-order" approximation that direct radiative aerosol forcing occurs only in cloud-free regions is shown to be correct only for nonabsorbing aerosols and only as cloud albedo approaches unity. For strongly absorbing particles such as soot the presence of a cloud layer embedded within the aerosol layer actually enhances the heating effect of such particles. That enhancement continues to increase as cloud thickness increases, eventually reaching more or less an asymptotic value that can be as much as 3 times cloud-free forcing. The presence of a typical cirrus cloud layer above an aerosol layer leads to only modest changes of forcing from those in the absence of the cloud layer. Thus aerosol forcing in the presence of cirrus clouds cannot be neglected.

We show that an absorbing aerosol layer in the presence of an embedded cloud layer can lead to in-cloud solar heating rates that are, for the particular set of parameters considered here, up to $3 \%$ of the aerosol-free, in-cloud solar heating rates.

Acknowledgment. This work was supported by the National Science Foundation grant ATM-9614105.

\section{References}

Andreae, M., Climatic effects of changing atmospheric aerosol levels, in World Survey of Climatology, vol. 16, Future Climates of the World, edited by A. Henderson-Sellers, pp. 341-392, Elsevier, New York, 1995.

Boucher, O., and T. L. Anderson, General circulation model assessment of the sensitivity of direct climate forcing by anthropogenic sulfate aerosols to aerosol-size and chemistry, J. Geophys. Res., 100, 26,11726,134, 1995.

Charlson, R. J., J. Langner, H. Rodhe, C. B. Leovy, and S. G. Warren, Perturbation of the northern hemisphere radiative balance by backscattering from anthropogenic sulfate aerosols, Tellus, $43 A B$, 152-163, 1991.

Charlson, R. J., S. E. Schwartz, J. M. Hales, R. D. Cess, J. A. Coakley, J. E. Hansen, and D. J. Hofmann, Climate forcing by anthropogenic aerosol, Science, 255, 423-430, 1992.

Chuang, C.C., J.E. Penner, K.E. Taylor, A.S. Grossman, and J.J. Walton, An assessment of the radiative effects of anthropogenic sulfate, $J$. Geophys. Res., 102, 3761-3778, 1997.

Chylek, P., G. B. Lesins, G. Vidden, J. G. D. Wong, R. G. Pinnick, D. Ngo, and J.D. Klett, Black carbon and absorption of solar radiation by clouds, J. Geophys. Res., 101, 23,365-23,371, 1996.

d'Almeida, G.A., P. Koepke, and E.P. Shettley, Atmospheric Aerosols: Global Climatology and Radiative Characteristics, 261 pp., A. Deepak, Hampton, Va., 1991.

Feichter, J., U. Lohmann, and I. Schult, The atmospheric sulfur cycle in ECHAM-4 and its impact on the shortwave radiation, Clim. Dyn., 13, 235-246, 1997.

$\mathrm{Fu}, \mathrm{Q}$, and $\mathrm{K}$. N. Liou, Parameterization of the radiative properties of cirrus clouds, J. Atmos. Sci., 50, 2008-2025, 1993.

Hale, G. M., and M. R. Querry, Optical constants of water in the $200 \mathrm{~nm}$ to $200 \mathrm{~mm}$ wavelength region, Appl. Opt., 12, 555-563, 1973.

Hansen J., M. Sato, and R. Ruedy, Radiative forcing and climate response, J. Geophys. Res., 102, 6831-6864, 1997.
Haywood, J. M., and K. P. Shine, The effect of anthropogenic sulfate and soot on the clear sky planetary radiation budget, Geophys. Res. Lett., 22, 603-606, 1995.

Haywood, J.M., D.L. Roberts, A. Slingo, J.M. Edwards, and K.P. Shine, General-circulation-rnodel calculations of the direct radiative forcing by anthropogenic sulfate and fossil-fuel soot aerosol, J. Clim., 10, 1562-1577, 1997.

Intergovernmental Panel on Climate Change (IPCC), Climate Change 1994: Radiative Forcing of Climate, report to IPCC from the Scientific Assessment Working Group (WGI), Cambridge Univ. Press, New York, 1995.

Kiehl, J. T., and B. P. Briegleb, The relative roles of sulfate aerosols and greenhouse gases in climate forcing, Science, 260, 311-314, 1993.

Kim, Y. P., J. H. Seinfeld, and P. Saxena, Atmospheric gas aerosol equilibrium, I. Thermodynamic model, Aerosol Sci. Technol., 19, 157-181, 1993a.

Kim, Y. P., J. H. Seinfeld, and P. Saxena, Atmospheric gas aerosol equilibrium, II. Analysis of common approximations and activity coefficient calculation methods, Aerosol Sci. Technol., 19, 182-198, 1993b.

Liou, K. N., An Introduction to Atmospheric Radiation, 217 pp., Academic Press, San Diego, Calif., 1980.

Liou, K. N., Q. Fu, and T. P. Ackerman, A simple formulation of the delta-four-stream approximation for radiative transfer parameterization, J. Atmos. Sci., 45, 1940-1947, 1988.

National Research Council (NRC), A Plan for a Research Program on Aerosol Radiative Forcing and Climate, Nat. Acad. Press, Washington, D. C., 1996.

Nemesure, S., R. Wagener, and S. E. Schwartz, Direct shortwave forcing of climate by anthropogenic sulfate aerosol: Sensitivity to particle size, composition, and relative humidity, J. Geophys. Res., 100 , 26,105-26,1 16, 1995.

Penner, J. E., Carbonaceous aerosols in influencing atmospheric radiation: Black and organic carbon, in Aerosol Forcing of Climate, edited by R. J. Charlson and J. Heintzenberg, John Wiley, New York, 1995.

Penner, J. E., R. Dickinson, and C. O'Neill, Effects of aerosols from biomass burning on the global radiation budget, Science, 256, 1432$1434,1992$.

Pilinis, C., and J. H. Seinfeld, Continued development of a general equilibrium model for inorganic multicomponent atmospheric aerosols, Atmos. Environ., 21, 2453-2466, 1987.

Pilinis, C., S. N. Pandis, and J. H. Seinfeld, Sensitivity of direct climate forcing by atmospheric aerosols to aerosol size and composition, $J$. Geophys. Res., 100, 18,739-18,754, 1995.

Russell, P. B., S. A. Kinne, and R. W. Bergstrom, Aerosol climate effects: Local radiative forcing and column closure experiments, J. Geophys. Res., 102, 9397-9407, 1997.

Sloane, C. S., Optical properties of aerosols of mixed composition, Atmos. Environ., 18, 871-878, 1984.

Sloane, C. S., Effect of composition on aerosol light scattering efficiencies, Atmos. Environ., 20, 1025-1037, 1986

Sloane, C. S., and G. T. Wolff, Prediction of ambient light scattering using a physical model responsive to relative humidity: Validation with measurements from Detroit, Atmos. Environ., 19, 669-680,1985.

Sloane, C. S., J. G. Watson, J. C. Chow, L. C. Pritchett, and L. W. Richards, Size-segregated fine particle measurements by chemical species and their impact on visibility impairment in Denver, Atmos. Environ., 25A, 1013-1024, 1991.

Toon, O. B., J. B. Pollack, and B. N. Khare, The optical constants of several atmospheric aerosol species: Ammonium sulfate, aluminum oxide, and sodium chloride, J. Geophys. Res., 81, 5733-5748, 1976.

van de Hulst, H. C., Light Scattering by Small Particles, Wiley, New York, 470pp., 1957.

Wiscombe, W., and G. Grams, The backscattered fraction in two-strean approximations, J. Atmos. Sci., 33, 2440-2451, 1976.

World Climate Program (WCP), A preliminary cloudless standard atmosphere for radiation computation, WCP-112, World Meteorol. Organ., Geneva. 1986.

H. Liao and J. H. Seinfeld, Division of Engineering and Applied Science and Department of Chemical Engineering, California Institute of Technology, Pasadena, CA 91125. (e-mail: John Seinfeld seinfeld@cco.caltech.edu)

(Received September 4, 1997; revised November 25, 1997;

accepted November 26, 1997.) 